\title{
Visualization of Shear Cracks in a Reinforced Concrete Beam using the Digital Image Correlation
}

\author{
Asdam Tambusay, ${ }^{\#, *}$, Benny Suryanto ${ }^{*}$, Priyo Suprobo ${ }^{\#}$ \\ ${ }^{\#}$ Department of Civil Engineering, Institut Teknologi Sepuluh Nopember, Surabaya, 60111, Indonesia \\ *School of Energy, Geoscience, Infrastructure and Society, Heriot-Watt University, Edinburgh, EH14 4AS, United Kingdom \\ E-mail: asdam.tambusay13@mhs.ce.its.ac.idorat78@hw.ac.uk
}

*School of Energy, Geoscience, Infrastructure and Society, Heriot-Watt University, Edinburgh, EH14 4AS, United Kingdom

E-mail: B.suryanto@hw.ac.uk

${ }^{\# D e p a r t m e n t ~ o f ~ C i v i l ~ E n g i n e e r i n g, ~ I n s t i t u t ~ T e k n o l o g i ~ S e p u l u h ~ N o p e m b e r, ~ S u r a b a y a, ~ 60111, ~ I n d o n e s i a ~}$

E-mail:priyo@ce.its.ac.id

\begin{abstract}
A low-cost digital image correlation system is used to visualize the formation and propagation of concrete cracking in a reinforced concrete beam. The system employed comprises an ordinary digital camera, a remote image recording controller (a smartphone) and a freely-available, open-source image correlation software package Ncorr. In this paper, the application of this system is demonstrated to obtain a comprehensive time-lapse of longitudinal strain fields developing before and after the onset of shear cracking, thus allowing one to appreciate the mechanisms of shear failure in the beam fully. It is shown that the longitudinal strain fields obtained from the DIC system are in a good agreement with hand-drawn crack maps and that obtained from nonlinear finite element analysis.
\end{abstract}

Keywords - DIC, low-cost, Ncorr, reinforced concrete, shear, strain field.

\section{INTRODUCTION}

Shear is profoundly considered as one of the most significant challenges in the design of reinforced concrete members. When subjected to moment and shear, premature shear failure may occur in structural members containing little or no shear reinforcement such as in thick sections and wide beams [1-3] or in ordinary beams weakened by tensile forces [4]. Failure can also occur in heavily reinforced elements under unforeseen loading conditions such as earthquake [5-6]. Given that shear failure can be associated with the brittle nature of concrete, it is not uncommon that shear failure occurs suddenly, with little or even no warning.

Extensive studies has now been carried out to lucidly explain the mechanism of shear failure, which has formed several well-established theories. The studies are regarding the 45-degree truss analogy [7], the variable truss method [8], the strut-and-tie model [9] and more advanced concepts such as the modified compression field, the disturbed stress field, and the softened truss and the compressive force path method [10-13]. Some of these theories have now been adopted by the currently available design specifications, although many of them still rely on empirical equations which were based on regression analysis of experimental results with different test parameters. When used to predict the shear capacity of a simple member such as a beam, studies have shown that the predictions from these specifications vary to a considerable extent from one to another [14-15], suggesting that shear mechanism is still not fully understood.

From the mechanics' point of view, it is relatively straightforward to comprehend the mechanisms of shear in an elastic beam. The mechanics of shear in reinforced concrete beams is, however, more difficult to understand as this depends on the occurring internal mechanisms and the extent of cracking. In a beam reinforced with welldistributed longitudinal and transverse bars, uniform cracks can develop, and the primary load-carrying mechanism would be in the form of an internal truss comprising concrete compression struts and steel tensile ties $[16,17]$. In a shear critical reinforced concrete beam with little or no transverse reinforcement, cracking forms more locally and the shear behavior would rely on the commonly accepted vital mechanisms. Influencing factors related to these mechanisms 
include effective depth, amount and strain of longitudinal reinforcement, concrete strength and axial force [18]. However, these factors are often interrelated, making it difficult to understand their individual role(s) fully.

In this paper, an attempt to gain improved insight into the mechanisms of shear is made by observing the process of cracking in a reinforced concrete beam. An advanced yet simple-to-setup monitoring system based on the digital image correlation (DIC) is employed for this purpose.

DIC is a full-field, non-contact imaging technique which can be used for the measurement of surface deformation. This technique requires a speckle pattern to be applied to the surface of the object of interest, preferably in the form of high contrast, random speckle pattern (viz, white background and black pattern). Typical DIC system requires the use of one to two digital camera(s) and software employing an image registration algorithm. Using the software, the deformation of an object under different load stages can be tracked by comparing image(s) obtained as the deformation occurs to a reference image representing the undeformed state.

In this study, the open source two-dimensional DIC freeware Ncorr was employed to investigate the mechanism of shear failure. The freeware works by dividing the reference image into small subsections referred to as subsets [19]. These subsets are controlled by two parameters, namely subset radius, $r$, and subset spacing, $s$, which were set to be 3 and 5 pixels. For detailed information about Ncorr, the readers are referred to [19] and [20]. Results are compared with predictions from Response 2000 [21-22] and ABAQUS.

\section{MATERIAL AND METHOD}

\section{A. Test Specimen}

A series of reinforced concrete beams were fabricated and tested in the Concrete Laboratory of the Institute for Infrastructure and Environment at Heriot-Watt University in Edinburgh, but only the results of one beam is presented in this paper.

The beam had six longitudinal reinforcements: three as compression (top) bars and three others as tension (bottom) bars. Four additional transverse reinforcements (two at each end) were provided in the end regions, past the supports, and tied to the longitudinal bars. Figure 1 shows the schematic of the beam, with the dimensions and reinforcement details provided in Tables 1 and 2.

The beam was cast into a steel formwork with dimensions of $100 \times 150 \times 2000 \mathrm{~mm}^{3}$, along with three standard $100 \mathrm{~mm}$ cubes. Prior to casting, steel reinforcement in the form of a rectangular cage was first prepared. The cage was then placed inside the steel formwork on six plastic spacers, with the formwork firstly given a coat of proprietary release agent to ease demoulding.

The concrete used to construct the beam is presented in Table 3. The concrete mix had a water/cement ratio of 0.45 , coarse aggregate with a maximum aggregate size of $10 \mathrm{~mm}$, fine aggregate $(<4 \mathrm{~mm})$, CEM I 52.5N Portland cement to EN197-1 [23], and a high range water reducer (BASF MasterGlenium ACE499). Mixing was done in a single batch using a 100-litre pan mixer.
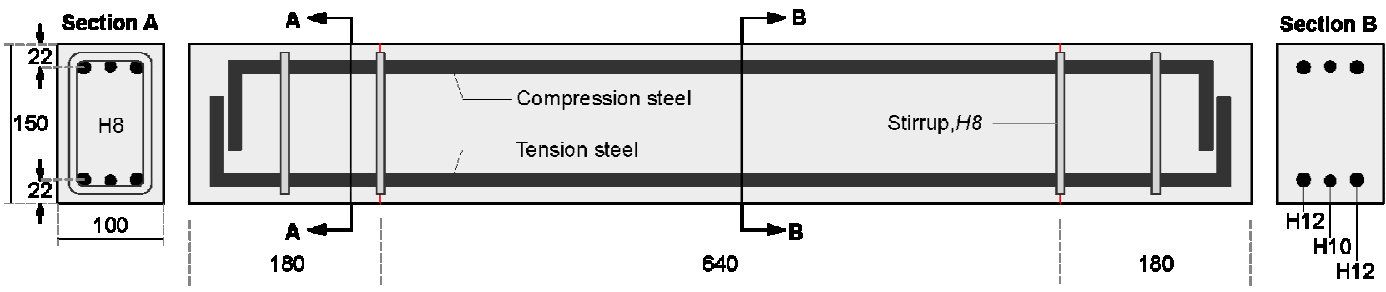

Fig. 1 Beam geometry and reinforcement layout (unit in millimetre).

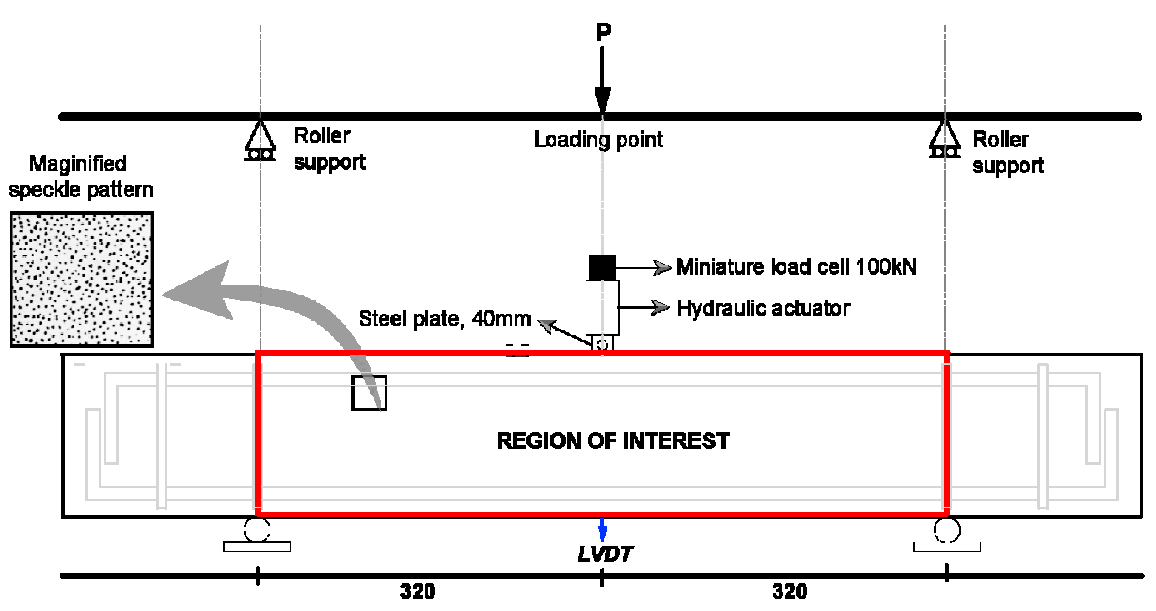

Fig. 2 Schematics of test setup and spackle pattern for DIC. 
TABLE I

DETAIL OF BEAM CROSS-SECTION

\begin{tabular}{|c|c|c|c|c|c|}
\hline Width, $b$ & Height, $h$ & Effective depth, $d$ & Length, $L$ & Span, $a$ & \multirow{2}{*}{ ald } \\
\cline { 1 - 5 }$(\mathrm{mm})$ & $(\mathrm{mm})$ & $(\mathrm{mm})$ & $(\mathrm{mm})$ & $(\mathrm{mm})$ & \\
\hline 100 & 150 & 125 & 1000 & 640 & 2.5 \\
\hline
\end{tabular}

TABLE II

TENSILE PROPERTIES OF REINFORCING STEEL

\begin{tabular}{|c|c|c|c|c|c|c|}
\hline Diameter & Area & $\begin{array}{c}\text { Yield } \\
\text { strength, } f_{v}\end{array}$ & $\begin{array}{c}\text { Ultimate } \\
\text { strength, } f_{u}\end{array}$ & $\begin{array}{c}\text { Elastic } \\
\text { modulus, } E_{s}\end{array}$ & $\begin{array}{c}\text { Strain } \\
\text { hardening, } \varepsilon_{s h}\end{array}$ & $\begin{array}{c}\text { Ultimate } \\
\text { strain, } \varepsilon_{u}\end{array}$ \\
\hline$(\mathrm{mm})$ & $\left(\mathrm{mm}^{2}\right)$ & $(\mathrm{MPa})$ & $(\mathrm{MPa})$ & $(\mathrm{GPa})$ & $\%$ & $\%$ \\
\hline 8 & 50.3 & 568 & 686 & 200 & 1.4 & 10.5 \\
\hline 10 & 78.5 & 593 & 723 & 200 & 1.7 & 9.5 \\
\hline 12 & 113.1 & 593 & 723 & 200 & 1.7 & 9.5 \\
\hline
\end{tabular}

TABLE III

CONCRETE MIX

\begin{tabular}{|c|c|c|c|c|c|}
\hline $10 \mathrm{~mm}$ & Sand & CEM I 52.5N & HRWR & w/c & $\mathrm{F}_{28}$ \\
\hline$\left(\mathrm{kg} / \mathrm{m}^{3}\right)$ & $\left(\mathrm{kg} / \mathrm{m}^{3}\right)$ & $\left(\mathrm{kg} / \mathrm{m}^{3}\right)$ & $\left(\mathrm{g} / \mathrm{m}^{3}\right)$ & $(-)$ & $(\mathrm{MPa})$ \\
\hline 1171 & 781 & 339 & 1071 & 0.45 & 43.4 \\
\hline
\end{tabular}

Notes: $10 \mathrm{~mm}$ is a graded crushed granite; HRWR is high range water reducer, and $\mathrm{F}_{28}$ is 28 -day mean compressive strength obtained from 3 samples of $100 \mathrm{~mm}$ cube.

\section{B. Test Setup}

The setup used to test the beam is shown in Figure 2. The beam was tested under three-point bending and placed onto two roller supports, with the span between the supports being $640 \mathrm{~mm}$ thereby giving a shear span-to-effective-depth ratio of 2.5. The load was applied using a hand-operated hydraulic jack in $5 \mathrm{kN}$ increments until failure. Cracks at each load increment were marked, and photos were also taken to document the crack pattern. The load was monitored using a miniature $100 \mathrm{kN}$ load cell attached to the head of the jack. Apart from load measurement, the beam deflection was recorded using a linear variable displacement transducer which was positioned beneath the beam at midspan. These test data were collected automatically using a data acquisition system at a sampling rate of $1 \mathrm{~Hz}$. One test took approximately one hour to complete.

\section{Automated Crack Mapping}

To perform automated crack mapping, the front surface of the beam was sprayed white and a random dot pattern was then made manually using a permanent marker (medium point size). This was done within a region of interest (ROI) marked with a red box in Figure 2. The ROI has overall dimensions of $150 \times 640 \mathrm{~mm}^{2}$.

In this study, a digital mirrorless camera Nikon J4 [24] was used to obtain the images of the front surface of the beam throughout testing. This camera had a built-in Wi-Fi system and featured high-resolution image acquisition $(5232 \times 3488$ pixels $)$. The camera was set up on a tripod and positioned parallel to the front surface of the beam at a distance approximately $500 \mathrm{~mm}$. Additional lighting was placed in front of the tripod and directed toward the region of interest with the purpose of eliminating the shadow effect as well as maintaining the white balance of the images throughout the loading process. Prior to loading, the first image was acquired to document the initial (undeformed) state. Subsequent digital images were then taken in $0.5 \mathrm{kN}$ increments throughout the loading process using a smartphone, with the communication to the camera via $\mathrm{Wi}$ Fi. The acquired digital images were manually edited to enhance image quality and then fed to a DIC freeware Ncorr V.1.2.1 [20, 24]. DIC analysis was then done on the ROI highlighted in Figure 2, with dimensions of approximately $2200 \times 520$ pixels.

\section{RESUlTS AND DisCUSSION}

\section{A. Load-Deflection and Crack Pattern}

A comparison of the observed and predicted loaddeflection curves of the beam is presented in Figure 3, along with the crack pattern obtained after failure in Figure 4.

With regard to the experiment result, it is apparent that the initial response is linear elastic, depicting a significant increase in load with a subtle increase in beam deflection. This continues until the load reaches $\sim 15 \mathrm{kN}$ when flexural crack forms for the first time on the tension face of the beam over the centre span (see Figure 4(a)). The load upon this initial cracking is still proportional to the deflection, although the two exhibit lower stiffness. This stiffness reduction is due to the initiation of flexural cracks which propagate towards the top of the beam with increasing loading. At a load of $45 \mathrm{kN}$, a more significant stiffness 
reduction occurs due to the formation of the first diagonal crack and further widening of two flexural cracks beneath the loading plate (see Figure 4(a)). As the load is further an opposite trend. Nevertheless, both approaches are shown to predict the correct mode of failure successfully. The lower-than-observed load capacity is not dissimilar to

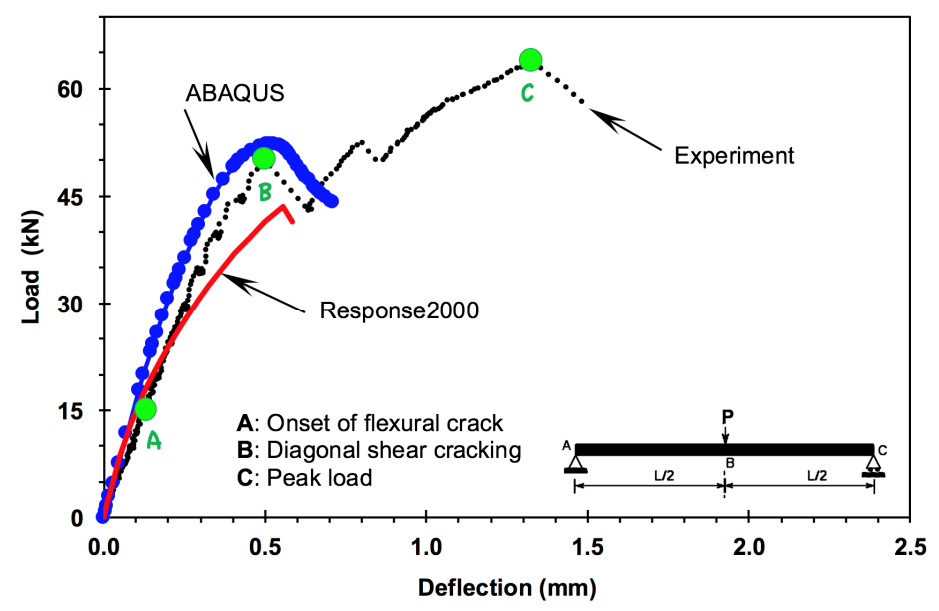

Fig. 3 Comparison of observed and predicted load-deflection responses.

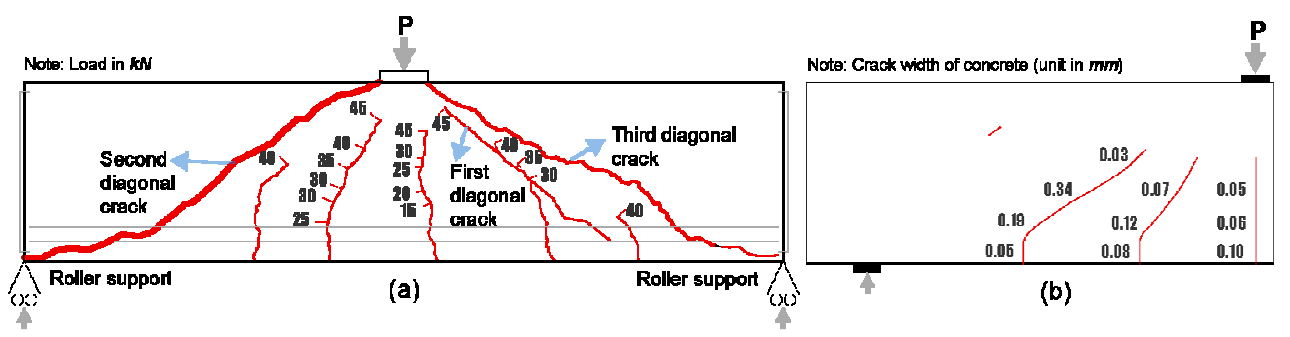

Fig. 4 (a) Crack pattern observed after failure and (b) predicted crack pattern from Response 2000.

increased, a significant drop in load occurs at $50 \mathrm{kN}$ due to sudden formation of the second diagonal crack in the lefthand side of the beam, which quickly propagates toward the tip of the loading place and the support (see Figure 4(a)). However, further propagation of the crack is prevented by dowelling actions of the tension and compression bars in addition to aggregate interlock of the concrete at the tip of the crack next to the loading plate, with the latter being enhanced due to lateral confinement provided by the compression bars. As the beam is further loaded, the third diagonal shear crack forms at the other end of the beam. This crack is, however, less critical as the propagation is again prevented. The beam eventually fails in shear at a load 64 $\mathrm{kN}$ due to sudden widening of the second diagonal crack in the left-hand side of the beam. Overall, the results suggest that compression bars have a role to play in delaying the occurrence of brittle shear failure and hence the increase in shear resistance. The presence of compression bars does not, however, alter the mode of failure; the beam still thus fails in a brittle manner.

Referring to the predicted load-deflection curves presented in Figure 4, it is apparent that both Response 2000 and ABAQUS show a reasonable agreement with the experimental results, in terms of overall response and stiffness, although both predictions underestimate the actual load capacity. More specifically, the results show that Response 2000 underestimates both the post-cracking stiffness and the load that corresponds to the formation of the critical diagonal shear crack, whereas ABAQUS shows general conception that considering the brittle nature of shear, the load that corresponds to the formation of critical diagonal cracks is generally considered as the failure load in design.

\section{B. DIC Results}

To provide a better picture of the initiation and propagation of the cracks, the longitudinal strain fields obtained from the front face of the beam at different stages of loading are presented in Figure 5(a), with the predicted strain field presented in Figure 5(b) for comparative purposes. Five stages of loading selected for discussion purposes. The stages represent the load corresponding to initial cracking $(\sim 15 \mathrm{kN})$ when flexural cracks have well developed. Before the formation of the diagonal shear crack $(35 \mathrm{kN})$, the load corresponding to the formation of the first diagonal shear crack $(45 \mathrm{kN})$. The load corresponding to the formation of the critical diagonal crack $(50 \mathrm{kN})$, and the ultimate load before failure $(\sim 64 \mathrm{kN})$.

It is apparent from Figure 5(a) that, during the early phase of loading ( $15 \mathrm{kN}$; image \#1), cracking results in a weakly development of strain localisations at the bottom of the beam, as indicated by a series of strips (in cyan colour). As the loading is increased, these localized strains become more prominent and increase primarily in length towards the top of the beam, indicating crack propagation (images \#2). It appears that the increase in crack width is relatively insignificant, implying that crack opening is very subtle thereby making the cracks challenging to spot with naked 
eyes (for illustration see the predicted crack width in Figure 4(b)). The first major diagonal crack forms at a load of $45 \mathrm{kN}$ (image \#3), which is not dissimilar with the crack pattern shown in Figure 3. At this stage, no further significant widening can be seen from the previously developed flexural cracks. At a load of $50 \mathrm{kN}$, the inclined crack develops for the first time, as indicated by the narrow region of high strain developing at the left side of the beam. It can be seen from Figure 5(a) that the crack has extended over the entire shear span between the support and the load point yet it does not lead to immediate failure. As the beam is further loaded, however, the propagation of this crack tends to cease, with the bottom tip stopped above the tension bar nearby the support, whereas the crack tip at the other end stops nearby the loading plate, which can be associated with the contribution of aggregate interlock. As the load further increases, a new inclined strain band can be seen at the right side of the beam next to the previously formed diagonal shear crack (image \#5). Failure finally occurs when the shear transfer contributed by the aggregate interlock is reached, leading to an immediate brittle shear failure.

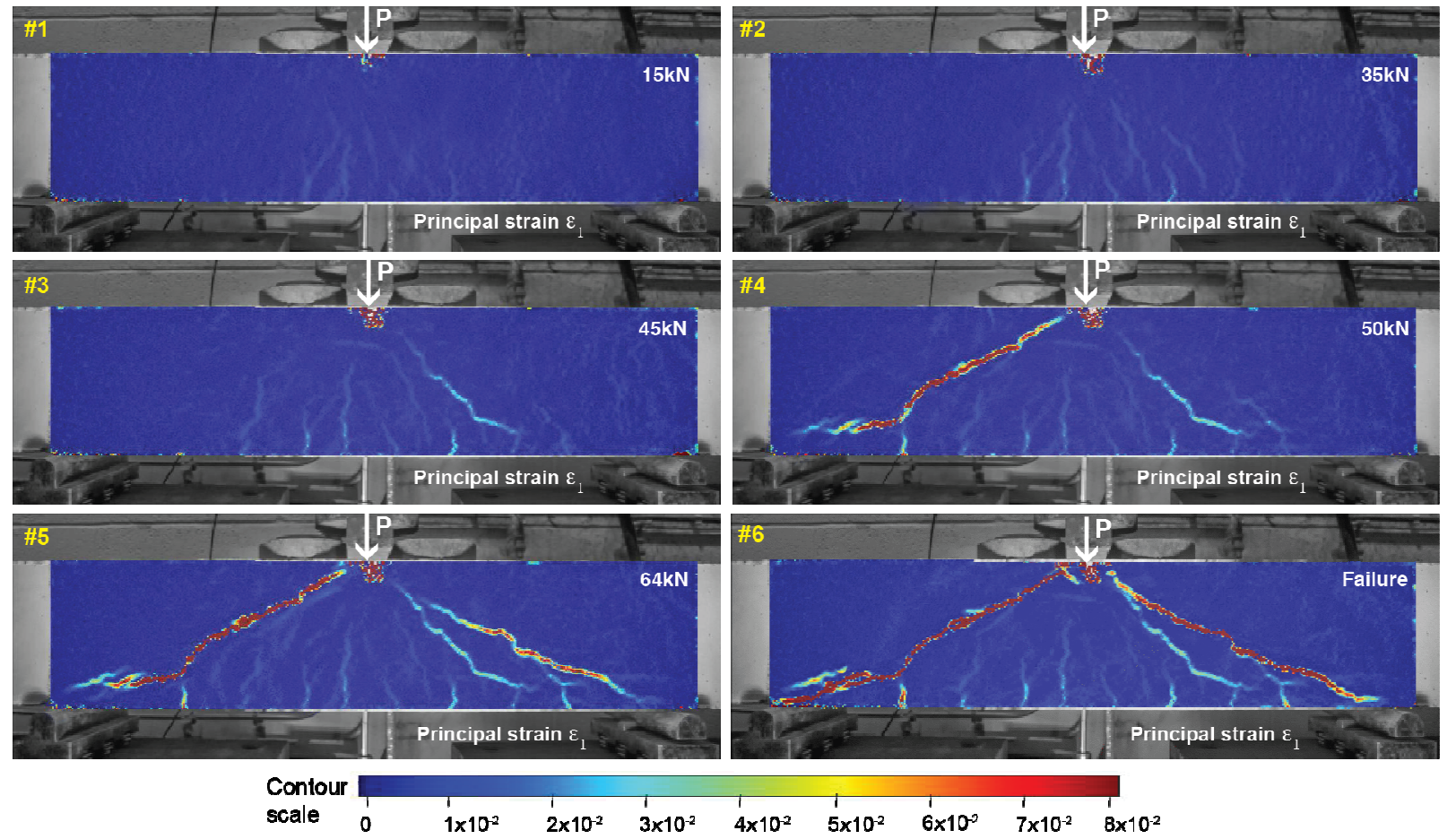

(a)
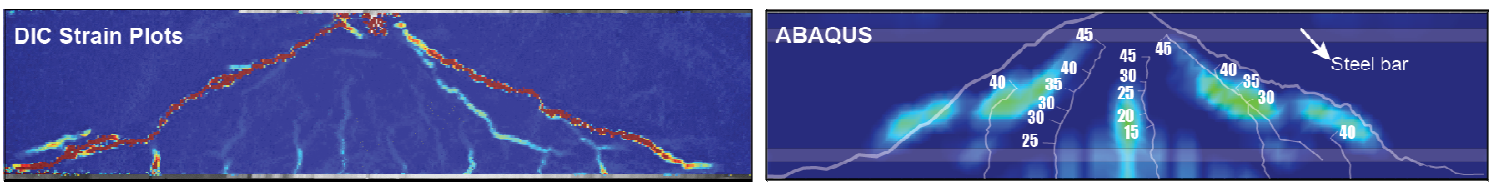

(b)

Fig. 5. Longitudinal strain plots: (a) computed longitudinal strains obtained from the surface of the beam using DIC, (b) comparison of the strain maps obtained from the DIC and ABAQUS, with the longitudinal reinforcement and the crack pattern observed from the back surface of the beam overlaid.

The longitudinal strain profile at peak load obtained from ABAQUS is presented in Figure 5(b), with the position of the longitudinal bars and the actual crack pattern overlaid in the figure for comparative purposes. The figure represents the predicted strain field from ABAQUS resembles the strain field measured from the DIC technique reasonably well.

\section{CONCLUSIONS}

An experimental examination into the shear behavior of the reinforced concrete beam is presented. Emphasis has been made on the application of a low-cost digital image correlation system and to check whether this system has sufficient quality to capture and track the formation and propagation of concrete cracking in a reinforced concrete beam. The low-cost DIC system employed comprises an ordinary digital camera, a remote image recording controller (a smartphone) and a freely-available, open-source image correlation software package Ncorr. The results of nonlinear numerical analysis have also been included in this study for comparative purposes. Based on the experimental and analytical work presented, the following conclusion can be drawn: This work demonstrates that DIC is emerging as powerful means of studying of various aspects of the mechanism of shear failure in reinforced concrete. The results show that the proposed DIC system has an adequate resolution to monitor the initiation and propagation of shear cracking in a reinforced concrete beam despite the limited crack width $(<0.2 \mathrm{~mm})$. It is shown from the DIC results that concrete cracking manifests itself as a series narrow strips of high (localised) strain. The magnitude of strain is shown to 
increase with increasing loading, indicating an increase in crack width. The longitudinal strain fields obtained from the DIC system employed in this study is shown to compare well with hand-drawn crack maps and strain-field obtained from nonlinear finite element analysis.

\section{ACKNOWLEDGMENT}

The authors wish to acknowledge the financial support from the Ministry of Research, Technology, and Higher Education of the Republic of Indonesia (Grant No. 1166/D3.2/PG/2016) and from the School of Energy, Geoscience, Infrastructure, and Society at Heriot-Watt University.

\section{REFERENCES}

[1] A. Uzel, E. C. Bentz, and M. P. Collins, "Design of indirectly loaded large footings for one-way shear," ACI Structural Journal, vol. 113, no. 3, pp. 491-501, 2016.

[2] M. P. Collins, E. C. Bentz, P. T. Quach, and G. T. Proestos, "The challenge of predicting the shear strength of very thick slabs," ACI Structural Journal, vol. 37, no. 11, pp. 29-37, 2015.

[3] M. P. Collins, E. C. Bentz and E. G. Sherwood, "Where is shear reinforcement required? Review of research results and design procedures," ACI Structural Journal, vol. 105, no. 5, pp. 590-600, 2008.

[4] L. Xie, E. C. Bentz, and M. P. Collins, "Influence of axial stress on shear response of reinforced concrete elements," ACI Structural Journal, vol. 108, no. 6, pp. 745-754, 2011.

[5] B. I. Bae, J. H. Chung, H. K. Choi, H. S. Jung, and C. S. Choi, "Experimental study on the cyclic behavior of steel fiber reinforced high strength concrete columns and evaluation of shear strength," Engineering Structures, vol. 157, pp. 250-267, 2018.

[6] K. Maekawa and X. An, "Shear failure and ductility of RC columns after yielding of main reinforcement," Engineering Fracture Mechanics, vol. 65, no. 2, pp. 335-368, 2000.

[7] Mörsch, "Der eisenbetonbau," 3rd ed., Engineering News Publishing Co., New York, 1908, (published in English as "Concrete-steel construction").

[8] H. Kupfer, "Erweiterung der Morschschen Fachwerkanalogie mit Hilfe des Prinzips vom Minimum Formanderungarbeit," (published in English as "Extension to the truss-analogy").

[9] L. Zhou, Z. Liu, and Z. He, "Elastic-to-plastic strut-and-tie model for deep beams," Journal of Structural Engineering," vol. 23, no. 4, pp. 04018007(1-14), 2018.
[10] F. J. Vecchio and M. P. Collins, "The modified compression-field theory for reinforced concrete elements subjected to shear," ACI Journal, vol. 83, no. 2, pp. 219-231, 1986.

[11] T. D. Hrynyk and F. J. Vecchio, "Capturing out-of-plane shear failures in the analysis of reinforced concrete shells," ASCE Journal of Structural Engineering, vol. 141, no.12, pp. 04015058, 2015.

[12] C. H. Luu, Y. L. Mo, and T. T. C. Hsu, "Development of CSMMbased shell element for reinforced concrete structures," Engineering Structures, vol. 132, no. 1, pp. 778-790, 2017.

[13] M. D. Kotsovos, "Compressive force path concept: basis for reinforced concrete ultimate limit state design," ACI Structural Journal, vol. 85, no. 1, pp. 68-75, 1988.

[14] T. Zang, P. Visintin, and D. J. Oehlers, "Shear strength of RC beams without web reinforcement," Australian Journal of Structural Engineering," vol. 17, no. 1, pp. 87-96, 2016.

[15] H. G. Kim, C. Y. Jeong, M. J. Kim, Y. J. Lee, J. H. Park, K. H. Kim, "Prediction of shear strength of reinforced concrete beams without shear reinforcement considering bond action of longitudinal reinforcements," Advances in Structural Engineering, vol. 21, no. 1, pp. 30-45, 2018.

[16] C. Hou, T. Nakamura, T. Iwanaga, J. Niwa, "Shear behavior of reinforced concrete and prestressed tapered beams without stirrups," Journal of JSCE, vol. 5, no. 1, pp. 170-189, 2017.

[17] B. Suryanto, K. Nagai, and K. Maekawa, "Smeared-crack modeling of R/ECC membranes incorporating an explicit shear transfer model," Journal of Advanced Concrete Technology, vol. 8, no. 3, pp. 315-326, 2010.

[18] E. C. Bentz and M. P. Collins., "Updating the ACI Shear Design Provisions," Concrete International, vol. 39, no. 9, pp. 33-37, 2017.

[19] J. Blaber, B. Adair, and A. Antoniou, "Ncorr: open-source 2D digital image correlation matlab software," Experimental Mechanics, vol. 55, no. 6, pp. 1105-1122, 2015.

[20] http://www.ncorr.com/download/ncorr_v1_2_1.zip (accessed 8 January 2017)

[21] E. C. Bentz, "Sectional analysis of reinforced concrete members," PhD Thesis, University of Toronto, Toronto, Canada, 2000.

[22] B. Suryanto, R. Morgan, and A. L. Han, "Predicting the response of shear-critical reinforced concrete beams using Response-2000 and SNI 2847:2013," Civil Engineering Dimension, vol. 18, no. 1, pp. $16-24,2016$.

[23] BS EN 197-1: 2011, "Cement: composition, specifications, and conformity criteria for common cements," British Standards Institution, London, UK, 2000.

[24] B. Suryanto, A. Tambusay, and P. Suprobo, "Crack mapping on shear-critical reinforced concrete beams using an open source digital image correlation software," Civil Engineering Dimension, vol. 19, no. 2, pp. 93-98, 2017. 